\title{
Perceptions among Swedish hospital physicians on prescribing of antibiotics and antibiotic resistance
}

\author{
I Björkman, ${ }^{1}{ }^{12}$ J Berg, ${ }^{1}$ M Röing, ${ }^{2}$ M Erntell, ${ }^{3}$ C S Lundborg ${ }^{1,4}$
}

1 Division of Global Health, IHCAR, Department of Public Health Sciences, Karolinska Institutet, Stockholm, Sweden ${ }^{2}$ Department of Public Health and Caring Sciences, Health Services Research, Uppsala University, Uppsala, Sweden ${ }^{3}$ Department of Communicable Disease Control, County Hospital, Halmstad, Sweden ${ }^{4}$ Nordic School of Public Health and Apoteket AB, Göteborg, Sweden

\section{Correspondence to} Ingeborg Björkman, Division of International Health, IHCAR, Department of Public Health Sciences, Karolinska Institutet, SE 17177 Stockholm, Sweden; ingeborgbjorkman@hotmail. com

Accepted 6 March 2009 Published Online First 1 July 2010
ABSTRACT

Objective To explore and describe perceptions of antibiotic prescribing among Swedish hospital physicians, with special reference to whether the perceptions included awareness of antibiotic resistance (AR).

Design A phenomenographic approach was used and data were collected in face-to-face interviews.

Setting Hospitals in seven different counties in central Sweden.

Participants A strategic sample of 20 hospital physicians specialising in internal medicine, surgery or urology.

Main outcome The variation of perceptions of antibiotic prescribing.

Results Five qualitative different perceptions were found. AR was considered in two of the perceptions. Reasons for not considering AR included a dominating focus on the care of the patient combined with lack of focus on restrictive antibiotic use, or uncertainty about how to manage infectious diseases or the pressure from the healthcare organisation. Parallels between the five perceptions and the stages in the transtheoretical model of health behaviour change were seen.

Conclusions In three of the perceptions, AR was not considered when antibiotics were prescribed. Physicians who primarily express these three perceptions do not seem to be prepared to change to restrictive prescribing. Our findings can be useful in designing activities that encourage $A R$ prevention. Organisational changes are also needed.

Increase in antibiotic resistance (AR) is a global problem that requires attention. ${ }^{1}$ The level of AR is related to the level of antibiotic use. ${ }^{2} 3$ To prevent an increase in AR development, restrictive prescribing is recommended. ${ }^{4}$ Several factors influencing the prescription of antibiotics have been proposed, for instance, awareness of AR among physicians ${ }^{56}$ and patients' demands for antibiotic treatment. ${ }^{7}$ However, a decisive factor is certainly how the prescribers actually perceive antibiotic prescribing because the way people act is related to how they perceive certain phenomena. Many studies on physicians' perceptions and attitudes to antibiotic prescribing focus on primary care practitioners; studies on hospital physicians are less frequent. However, although they are not the major antibiotic prescribers, hospital physicians are important because they often serve as role models for primary care practitioners. ${ }^{8}$ The aim of this study was to explore and describe perceptions among Swedish hospital physicians of how antibiotics are prescribed, with special reference to whether the perception included awareness of AR.

\section{METHOD}

\section{Study design}

This study was conducted with a phenomenographic approach. ${ }^{9}$ Phenomenography is a qualitative method designed to identify and describe perceptions in a group of people and has been used to explore perceptions among healthcare professionals. ${ }^{10-14}$ Data in a phenomenographic study are commonly collected in face-to-face interviews. A total of 20 interviews are regarded as sufficient to identify the variation of perceptions. ${ }^{15}$ The result of a phenomenographic study is presented as categories of descriptions, which are the researchers' abstraction of perceptions. Furthermore, an outcome space is created, which shows how the categories of description relate to each other. ${ }^{16}$

\section{Participants}

A strategic sample of 20 hospital physicians was recruited. The strategy was to include hospital physicians with different experiences of antibiotic prescribing to gain a rich and varied interview material. Thus, we selected physicians from different hospitals and counties, different specialities, with various lengths of professional years, and a reasonable mix in age and sex.

The physicians were first contacted by email. The purpose of the study was described. The physicians were informed that their participation was voluntary and that they could withdraw at any time without giving a reason. Confidentiality was guaranteed. Twenty-eight physicians were asked to participate and 20 accepted. Table 1 presents information about participants.

\section{Data collection}

All interviews were conducted by one of the authors (JB) in May/June 2005. The interviews lasted 25-90 min, were semistructured and followed a common interview guide. Questions were constructed to help the participants focus on actual situations when they had prescribed antibiotics. This was done by asking them to recall a specific situation experienced during routine clinical practice and to describe the situation, including how the decision to prescribe antibiotics was made. The question was repeated and a second situation was examined. At the end of the interview, participants were asked for their general opinions regarding the development of AR. All interviews were held during the physicians' work time in a quiet room at the hospital. Nineteen interviews were tape-recorded and transcribed verbatim. In one case, thorough notes were taken during the interview because the physician did not agree to be tape-recorded. Immediately after the session, the whole interview was written. 
Table 1 Demographics of participants

\begin{tabular}{llll}
\hline $\begin{array}{l}\text { Age } \\
\text { (years) }\end{array}$ & $\begin{array}{l}\text { Urology } \\
\text { (total) }\end{array}$ & $\begin{array}{l}\text { Surgery } \\
\text { (total) }\end{array}$ & $\begin{array}{l}\text { Internal } \\
\text { medicine } \\
\text { (total) }\end{array}$ \\
\hline $31-40$ & & 1 & 1 \\
$41-50$ & 2 & 2 & 4 \\
$51-60$ & 3 & 1 & 5 \\
$61-70$ & 5 (1 woman) & 5 (1 woman) & 10 (2 women) \\
Total &
\end{tabular}

The number of female physicians is small. However, the proportion of female physicians in Sweden in 2005 was similar to the proportion in our study (internal medicine $31 \%$, surgery $14 \%$ and urology $11 \%$ female physicians). The medical specialities were selected because of expected experience of treating patients with infections or for perioperative prophylaxis.

\section{Analysis}

The analysis was done by the first author (IB) and aimed at finding the variation of perceptions in the group of physicians as outlined by phenomenographic theory. ${ }^{9}$ The statements in all interviews were analysed together. From this meaning pool the categories emerged. Thus, findings relate to the group, not to individuals. The analysis can be described in five steps (see table 2). MR acted as co-reader. This meant that she first read all interviews for an overall impression of the content. Then she studied the preliminary categories of description and judged whether these were reasonable, after reflection on what was said in the interviews. After this a discussion was held between analyst and co-reader to establish final categories and create an outcome space.

\section{FINDINGS}

Five categories of description were identified, representing five qualitatively different perceptions. A basic concept expressed in all categories concerned the patient; today's patient must be cared for and properly treated. There was also a general awareness of the existence of AR. However, this awareness was to various degrees either held in the foreground or in the background and thus had different meanings in different perceptions. Furthermore, infectious disease specialists were mentioned in all perceptions. However, the relationships to them varied.

The findings are reported as categories of descriptions, and the relationships among categories are shown in the outcome space (see figure 1). In this study, more awareness of AR when antibiotics are prescribed corresponded to a more complex perception. Categories are described in table 3; each category is illustrated by a quotation.

\section{Table 2 Analysis described in five steps}

1. First, the transcripts were read several times to establish familiarity with the contents and to outline preliminary categories of description. At this stage the focus was on the meaning embedded in all the texts together. During the analysis this question was kept in mind: what does this statement tell me about how this physician perceives antibiotic prescribing and how he or she considers AR?

2. All interviews were read again and the preliminary categories were described in words. A loose structure of the logical relation among categories was created. Here, focus was kept on the meaning but also on the structure of meanings.

3. The interviews were read once again and summaries of each interview were written down. During this reading the focus was on the meaning in each interview but in relation to all texts as a whole.

4. All summaries were grouped according to similarities and differences and formed into categories, if possible close to the preliminary categories of description. Here the focus was on the preliminary categories. Adjustments were made again and the descriptions of categories were revised.

5. At this point the analysis was presented to one of the authors who acted as coreader (MR). In a discussion between the two researchers, the categories were revised once again and the outcome space was established.

AR, antibiotic resistance.

There are different ways to perform a phenomenographic analysis in practice. ${ }^{16}$ In this study the procedures used have similarities to the analysis described by Prosser. ${ }^{17}$

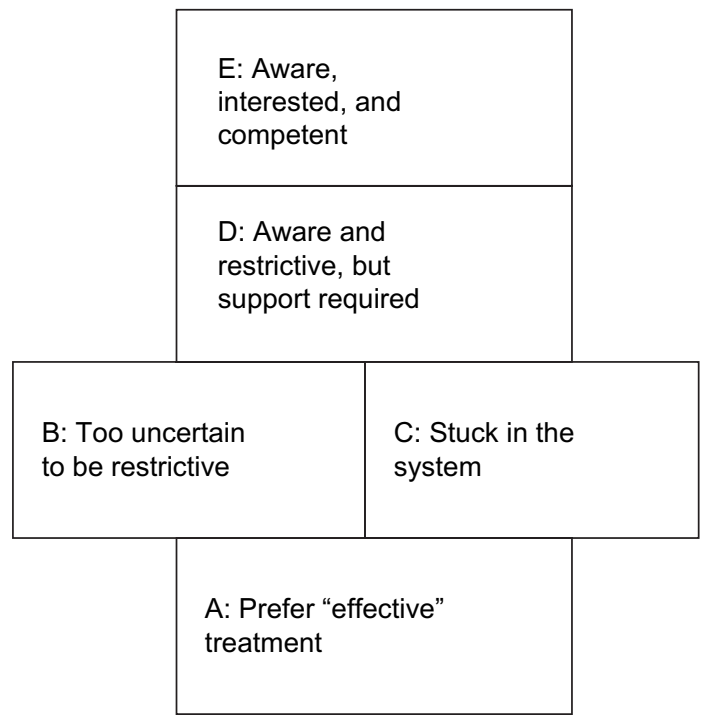

Figure 1 This outcome space illustrates the logical relationship among the five identified categories of description A-E. In an outcome space a categry that is more complex is placed at a higher level, above categories that are less complex. Aspects building up the categories: 1) Care of patient, 2) Guidelines 3) Restrictive prescribing, and 4) Special interest in infectious disease treatment. Aspects included in the categories: $A$ includes 1; B and $C$ include 1 and 2; $D$ includes 1, 2 and 3; and $\mathrm{E}$ includes 1, 2, 3 and 4.

\section{DISCUSSION}

This is one of the first studies exploring hospital physicians' perceptions of antibiotic prescribing. The most important contribution is that it presents a new way to describe how physicians perceive antibiotic prescribing in hospital care. The analysis focused especially on whether the perceptions included awareness of AR. Five qualitatively different perceptions were identified; in two of them, AR was considered when prescribing antibiotics, and in three, AR was not considered.

A major factor that influenced perception was whether the physician had a special interest in infectious disease management or not. We found that only in the most complex perception was there a clear expression of this interest (Aware, interested and competent). In all other perceptions, the concept was that other areas were more important and interesting. Obviously, special competence is necessary to use antibiotics with narrow-spectrum and short treatment periods (which theoretically is more beneficial from a resistance development perspective) to avoid the feeling that the patient's life and health is jeopardised.

In perception $\mathrm{D}$ (Aware and restrictive, but support required), the perception was that it is possible to use less aggressive antibiotic treatment strategy in most patients. This concept had developed despite lack of special interest in treatment of infectious diseases. Instead, this had developed from close collaboration with colleagues with such special interests, either physicians in the same departments or infectious disease specialists. The importance of these colleagues was emphasised, and to maintain this perception, close support from an infectious disease specialist is probably necessary.

In perception $\mathrm{B}$, the barrier for restrictive antibiotic prescribing expressed by the physicians was the uncertainty of how to manage infectious diseases. Lack of such knowledge among physicians has been reported in earlier studies (see below). Thus, to encourage restrictive antibiotic prescribing, physicians must be reinforced in the management of infectious 
Table 3 Description of the five identified categories

\begin{tabular}{|c|c|c|}
\hline Category of description & Description & Quotation \\
\hline A. Prefer "effective" treatment & $\begin{array}{l}\text { In this perception the basic notion was that the } \\
\text { patient of today must be treated. However, } \\
\text { infections, antibiotics and AR were of no interest } \\
\text { in this perception. Therefore, to be sure that the } \\
\text { patient would be cured, broad-spectrum } \\
\text { antibiotics were selected. It was known that these } \\
\text { antibiotics were not recommended, but in spite of } \\
\text { this, they were chosen because they were } \\
\text { perceived as effective. The threat of AR was }\end{array}$ & $\begin{array}{l}\text { "The same antibiotics are used in treatment as in } \\
\text { the prophylaxis, as I told you about. This is not so } \\
\text { good, I know, but this is the way it is. Theory is } \\
\text { theory but this is practice. That's why it is rather } \\
\text { common that fluoroquinolones are also used in } \\
\text { uncomplicated UTI. ... Yes, I have seen resistant } \\
\text { bacteria sometimes, with for example Lexinor. But } \\
\text { this is nothing I have been thinking about." } \\
\text { (Interview 19) }\end{array}$ \\
\hline
\end{tabular}

B. Too uncertain to be restrictive

C. Stuck in the healthcare system

D. Aware and restrictive, but support required

E. Aware, interested and competent perceived as a theoretical problem and was not

kept in mind when antibiotics were prescribed.

In this category the main focus was also on the patient of today, but in addition there was a general notion that guidelines of restrictive treatment of infectious diseases should be followed. A restrictive treatment was, however, not practiced and the barrier for this was the physician's uncertainty. The uncertainty seemed to be a consequence of low interest in antibiotics and treatment of infectious diseases. It was expressed that narrow-spectrum antibiotics were considered but often regarded as not effective enough. Accordingly, to make the physician feel certain, extra doses of antibiotics were used as well as broader-spectrum antibiotics. Some physicians reflected on the consequences of their uncertainty, whereas others did not.

This perception has similarities with $B$ but here the barrier for a restrictive treatment was the healthcare system. It was said that hospital care today means high tempo, many patients to take care of in a short time and a constant struggle to find free beds. Consequently, hospitalised patients must be effectively treated so they can be discharged as quickly as possible. The "wait and see" philosophy was not accepted any longer, and patients could not be brought back for follow-up visits. Accordingly, it was expressed that treatment today was often more potent than necessary.

In perception $\mathrm{D}$ the concept was, as in $\mathrm{B}$ and $\mathrm{C}$ that the patient must be treated and guidelines for restrictive treatment should be followed. The difference was that here this was done in practice. As in perception $B$, infectious diseases were not of the highest interest. The strategy was to follow guidelines carefully, which here included the safe use of antibiotics with narrow spectrum in the treatment of most patients. Support from infectious disease specialists was considered necessary. Awareness of $A R$ and the active prevention of $A R$ had often been introduced by a colleague or an infectious disease specialist. In this perception infectious diseases were a major interest and accordingly the treatment of patients was more diverse. It was often possible to use narrow-spectrum antibiotics and still guarantee the safety of the patient because the physician knew how to manage serious infections. In this conception the infectious disease specialists were important for updating of competence, but the treatment was most of the time managed without specialist counselling.
"I think that we, because of uncertainty, may be somewhat more active. And for the same reason that we sometimes give more broad spectrum antibiotics than they do for example at the department of infectious diseases, it will be... When you do not know, you use something stronger." (Interview 6)

"Previously they were kept in the hospital to rest the intestine, today they are sent home with two antibiotics. ... I think, that when we are not able to bring the patients back for a second visit, it makes us incautious and makes us use more [antibiotics] than we used before." (Interview 5)

"So in all treatment with antibiotics this [antibiotic resistance] is, so to speak, kept in one's mind.... To be frank, this is not exactly my main area of interest, and then you follow these recommendations and guidelines we get from the department of infectious diseases." (Interview 4)

"Yes, this [infectious diseases] is a major part of our work. ... If you have an infection unit [at the hospital] it may look different than here, but for us infections are a very large part of our activities, I would say." (Interview 17)

$A R$, antiobiotic resistance.

Each category is illustrated by a quotation

disease treatment; probably both education and restrictive prescribing experience are needed.

An important message to policy-makers and hospital managers is given in perception $\mathrm{C}$ (Stuck in the healthcare system). It was clearly stated that it is possible to use treatment methods that reduce the risk of $A R$, but the healthcare system develops in another direction and thus contributes to AR development. Most infections are not life-threatening, and it is often wise to wait and see how the disease develops before aggressive treatment strategies are chosen. ${ }^{3}$ Practicing these methods was, however, considered impossible in healthcare today. This finding is important and should not be ignored; the healthcare system must be organised in a way that supports restrictive antibiotic prescribing.

Many studies demonstrate that physicians do not practice restrictive antibiotic treatment. It has been suggested that a major 
Table 4 The transtheoretical model

\begin{tabular}{lll}
\hline Stage of change (Prochaska and Velicer ${ }^{26}$ ) & $\begin{array}{l}\text { Suggested correlation to our categories of } \\
\text { description }\end{array}$ \\
\hline Precontemplation & $\begin{array}{l}\text { Not aware of the problem; not interested } \\
\text { in taking action; tend to avoid reading, } \\
\text { talking or thinking about their high-risk } \\
\text { behaviours } \\
\text { Have intentions to change, know the pros } \\
\text { but are much aware of the cons } \\
\text { Have intentions to act in the near future, } \\
\text { have taken some action and have plans } \\
\text { for how to change }\end{array}$ & Category A \\
Preparation & $\begin{array}{l}\text { Act to a degree to reduce risk } \\
\text { Try to keep the new behaviour and avoid }\end{array}$ & Category D \\
Action & relapses & Category E \\
Maintenance & & \\
\hline $\begin{array}{l}\text { According to the model, behaviour change is a process involving five stages. Previous theories described behavioural change as an event. The right column shows } \\
\text { our suggestion of best correlation between identified perceptions and stages of change. Note that perceptions and stages include different aspects and cannot be } \\
\text { totally correlated. }\end{array}$
\end{tabular}

contributor to this problem is the healthcare tradition to overtreat infections. ${ }^{6}$ One reason for overtreatment could be patient demands for antibiotics ${ }^{6}$ or that the prescribers perceive they must balance their perceptions of what is clinically best for the patient with what they perceive will satisfy the patient. ${ }^{18}$ Patient demands or pressure to satisfy patients were, however, not issues in our study probably because patient demands are less clearly expressed in hospital care. It has been shown that physicians do not regard themselves as part of the AR problem; it is either only a problem in theory ${ }^{5}$ or a national problem far from their own horizons. 61920 Physicians seem to underestimate the AR problem's severity. ${ }^{20}$ General practitioners expressed that they have to consider many factors when deciding how to treat a patient with infection, and AR is not the most immediate factor. ${ }^{21}$ A reason for choosing a broad-spectrum antibiotic could be that the physician prioritises the patient's immediate needs over long-term issues. ${ }^{22}$ Some studies point to physicians' lack of knowledge of infectious disease treatment, ${ }^{20} 23-25$ which may result in difficulties assessing the infection's severity ${ }^{25}$ or uncertainty about how to switch from intravenous to oral antibiotics or from broad-spectrum antibiotics to narrow-spectrum antibiotics when laboratory results have arrived. ${ }^{24}$

Many of the issues presented as problems in the studies above could also be recognised in our study. However, by taking a phenomenographic approach, we present a new way of regarding the findings. Perceptions, according to phenomenographic theory, are inseparably intertwined with the persons' lived experiences and actions. ${ }^{9}$ Thus, when describing perceptions, it is possible to understand something about what the participants experience and what actions they take. We have described different perceptions among physicians, which reflect different ways to act when prescribing antibiotics.

Phenomenography has its roots in pedagogic research and was initially created to develop learning. ${ }^{9}$ Learning is considered an ongoing process, and new insights are gained by incorporating new aspects. Thus, there is an idea of development that can be applied to perceptions identified in a phenomenographic study. Examining our findings, we saw a development from perception $A$ to perception $\mathrm{E}$ in the expression of aspects important for restrictive antibiotic prescribing. Care of the patient, the only aspect included at the first level (A), was obvious and present in all five perceptions. The next level ( $B$ and $C$ ) included one more aspect, guidelines. Next level (D) included these two aspects plus a new aspect, restrictive prescribing. Finally, at the highest level (E), the three aspects were included, as well as a new aspect, special interest in infectious disease treatment.

Studying our findings, we found parallels between the different perceptions we identified and the various stages of health behaviour change, as described in the transtheoretical model ${ }^{26}$ (see table 4). The model explains that action-oriented health promotion activities often fail because most people are not ready to change; other activities are needed to influence people in the first stages of behavioural change. Insights from health promotion can probably be used in the promotion of AR prevention. This conception can be most useful for promoters of AR prevention. We suggest that physicians who primarily express the perceptions described in A, B and C are not ready for change. For instance, physicians with dominant perception A must first be convinced that the threat of $A R$ is real. Education about risks associated with inappropriate prescribing seems adequate.

The findings in this study are limited to how Swedish hospital physicians perceive the phenomena of prescribing antibiotics. We believe, however, that the findings can be used in other contexts; similarities to previous findings were seen and the possibility of finding correlations with the stages in the transtheoretical model strengthens our findings.

\section{CONCLUSIONS}

This study presents a new way to understand how hospital physicians perceive antibiotic prescribing. Five qualitatively different perceptions were found. AR prevention was practiced in two of the perceptions. In the other three, AR was not considered in treatment of infectious diseases. This was related to the lack of focus on AR, the feelings of uncertainty in managing infectious treatment or that healthcare system was a barrier. Specialists in infectious diseases play decisive roles in helping hospital colleagues in AR prevention.

Parallels were found between identified perceptions and stages in the transtheoretical model of health behavioural change. Physicians who primarily express the three perceptions where $A R$ was not considered do not seem to be ready to change to restrictive prescribing. Our findings can be useful in the development of activities directed at physicians who encourage AR prevention. It should be noted that, in addition to such activities, organisational changes are also needed

Acknowledgements We are most grateful to all hospital physicians who participated in this interview study, to Ulla Wihlman for valuable contributions in the discussion of findings and to Strama (Swedish strategic programme against AR) for providing funding making this study possible. We also thank one of the reviewers for valuable comments on an earlier version of the manuscript.

Funding Strama, the Swedish strategic programme against antibiotic resistance, funded this study.

Competing interests None.

Provenance and peer review Not commissioned; externally peer reviewed. 


\section{REFERENCES}

1. WHO. WHO global strategy for containment of antimicrobial resistance, 2001 WHO/CDS/CSR/2001.2. http://www.who.int/csr/resources/publications/drugresist/ en/EGlobal Strat.pdf (accessed 29 Apr 2008).

2. Albrich WC, Monnet DL, Harbarth S. Antibiotic selection pressure and resistance in Streptococcus pneumoniae and Streptococcus pyogenes. Emerg Infect Dis 2004; 10:514-17

3. van de Sande-Bruinsma N, Grundmann H, Verloo D, et al. Antimicrobial drug use and resistance in Europe. Emerg Infect Dis 2008;14:1722-30.

4. Odenholt I, André M. Infektioner (infectious diseases). (In Sweden). In: Läkemedelsboken (drug therapy handbook). Stockholm: Apoteket AB 2007:535-47.

5. Wester CW, Durairaj L, Evans AT, et al. Antibiotic resistance: a survey of physician perceptions. Arch Intern Med 2002;162:2210-16.

6. Giblin TB, Sinkowitz-Cochran RL, Harris PL, et al. Clinicians' perceptions of the problem of antimicrobial resistance in health care facilities. Arch Intern Med 2004;164:1662-8.

7. Metlay JP, Shea JA, Crossette LB, et al. Tensions in antibiotic prescribing: pitting social concerns against the interests of individual patients. J Gen Intern Med 2002;17:87-94.

8. Mason A. New medicines in primary care: a review of influences on general practitioner prescribing. J Clin Pharm Ther 2008;33:1-10.

9. Marton F, Booth S. Om lärande (also available in English: (1997) Learning and awareness. Mahwah, N.J., L. Erlbaum Associates, Inc.). Lund: Studentlitteratur, 2000

10. Dall'Alba G. Medical practice as characterised by beginning medical students. Adv Health Sci Educ Theory Pract 1998;3:101-18.

11. Stålsby Lundborg C, Wahlström R, Dall'Alba G. Ways of experiencing asthma management. Variations among general practitioners in Sweden. Scand J Prim Health Care 1999;17:226-31.

12. Holmström I, Jonsson AC, Rosenqvist U. Understanding the job in a new way-a basis for development of competence in diabetes care. Ups J Med Sci 2000;105:161-9.

13. Larsson J, Holmström I, Rosenqvist U. Professional artist, good Samaritan, servant and co-ordinator: four ways of understanding the anaesthetist's work. Acta Anaesthesiol Scand 2003;47:787-93.
14. Björkman IK, Bernsten CB, Schmidt IK, et al. The role of drug and therapeutics committees. Int J Health Care Qual Assur Inc Leadersh Health Serv 2005; 18:235-48

15. Sandberg J. Understanding human competence at work: an interpretative approach Acad Manage J 2000;43:9-17.

16. Akerlind GS. Variation and commonality in phenomenographic research methods. Higher Education Research \& Development 2005;24:321-34.

17. Prosser M. Some experiences of using phenomenographic research methodology in the context of research in teaching and learning. In: Bowden J, Walch $\mathrm{E}$, eds. Phenomenographic research: variations in method. Melbourne: RMIT, EQARD, 1994:31-43

18. Hart AM, Pepper GA, Gonzales R. Balancing acts: deciding for or against antibiotics in acute respiratory infections. J Fam Pract 2006;55:320-5.

19. Gould IM, Mackenzie FM, Shepherd L. Attitudes to antibiotic prescribing, resistance and bacteriology investigations amongst practitioners and patients in the Grampian region of Scotland. Eur J Gen Pract 2007;13:35-6.

20. Brinsley KJ, Sinkowitz-Cochran RL, Cardo DM. Assessing motivation for physicians to prevent antimicrobial resistance in hospitalized children using the Health Belief Model as a framework. Am J Infect Control 2005;33:175-81.

21. Simpson SA, Wood F, Butler CC. General practitioners' perceptions of antimicrobia resistance: a qualitative study. J Antimicrob Chemother 2007;59:292-6.

22. Wood F, Simpson S, Butler CC. Socially responsible antibiotic choices in primary care: a qualitative study of GPs' decisions to prescribe broad-spectrum and fluroquinolone antibiotics. Fam Pract 2007;24:427-34.

23. Mol PG, Rutten WJ, Gans RO, et al. Adherence barriers to antimicrobial treatment guidelines in teaching hospital, the Netherlands. Emerg Infect Dis 2004; 10:522-5.

24. Schouten JA, Hulscher ME, Natsch $\mathrm{S}$, et al. Barriers to optimal antibiotic use for community-acquired pneumonia at hospitals: a qualitative study. Oual Saf Health Care 2007:16:143-9.

25. Barlow G, Nathwani D, Myers E, et al. Identifying barriers to the rapid administration of appropriate antibiotics in community-acquired pneumonia. J Antimicrob Chemother 2008;61:442-51.

26. Prochaska J0, Velicer WF. The transtheoretical model of health behavior change. Am J Health Promot 1997;12:38-48. 